\title{
The Glomerular Mesangium
}

\section{KINETIC STUDIES OF MACROMOLECULAR UPTAKE IN NORMAL AND NEPHROTIC RATS}

\author{
S. Michafl Mauer, Alfred J. Fish, Edward B. Blau, and \\ Alfred F. Michael \\ From the Department of Pediatrics, University of Minnesota Medical School, \\ Minneapolis, Minnesota 55455
}

A B S T R A C T This study was designed to define quantitatively the function of the rat glomerular mesangium in the uptake and processing of intravenously administered protein macromolecules (radiolabeled aggregated human IgG, AHIgG- ${ }^{125} \mathrm{I}$ ), to relate this function to that of the general reticuloendothelial system, and to examine the effects of increased glomerular permeability to protein on the mesangial cell system.

Mesangial localization of human IgG as demonstrated by immunofluorescent microscopy showed good correlation with concentrations of AHIgG- ${ }^{128} \mathrm{I}$ in preparations of isolated glomeruli. In normal rats the concentrations of AHIgG- ${ }^{205} \mathrm{I}$ in glomeruli were similar to those of lung, liver, and spleen and demonstrated a rapid decrease with increasing time intervals after aggregate administration.

In rats given aminonucleoside of puromycin a marked increase in mesangial uptake of aggregates was found while studies of nephrotic lungs, liver, spleen, and blood showed no such differences. Glomerular levels of AHIgG${ }^{120} \mathrm{I}$ in aminonucleoside animals could not be correlated with the quantity of proteinuria.

Nephrotic and control animals given unaggregated human IgG showed little glomerular localization by immunofluorescent microscopy; no difference in the concentration of this protein in nephrotic as compared to control glomerular isolates was found.

Thus, the mesangium in normal animals functions in a manner analogous to that of the general reticuloendothelial system. In nephrotic rats the mesangial uptake

Dr. Mauer is a Fellow, Medical Research Council of Canada.

Dr. Fish is an Established Investigator of the American Heart Association.

Received for publication 26 August 1971 and in revised form 10 December 1971. of macromolecules is makedly increased, a finding not observed in other tissues.

\section{INTRODUCTION}

The mesangium is a poorly understood part of the glomerulus occupying, in man, approximately $8 \%$ of the glomerular surface area and containing $25 \%$ of the total number of glomerular cells (1). The mesangial cells occupy an intercapillary position separated from the capillary lumen, internally, by the endothelial cell cytoplasm and bounded externally by the glomerular basement membrane (2). Light, immunopathologic, and electron microscopic observations of the human kidney in a variety of diseases including anaphylactoid purpura nephritis (3), chronic membranoproliferative nephritis with hypocomplementemia (4), diabetic nephropathy (5), acute poststreptococcal nephritis (6), and lupus erythematosis ( 7 ) have demonstrated significant mesangial alterations. However, at present only very limited knowledge of the function of the mesangial system and its relationship to glomerular pathology is available.

Studies of the glomerular localization and transport of macromolecular tracer materials including thorotrast (8), ferritin (2), colloidal carbon (9), and globin (10) have demonstrated mesangial uptake of these substances after their injection into the circulation of normal animals. Thus, Farquhar and Palade have suggested that one function of the mesangium is the removal of filtration residues from the subendothelial space (2). More recently, Michael, Fish, and Good (11) showed that aggregated human gamma globulin, a polydisperse population of macromolecules having many of the properties of antigen-antibody complexes (12), localizes in the mouse glomerulus after intravenous injection. Immunofluorescent studies demonstrated that, within a few hours, there was transport of these aggregates to the 
mesangial region from which they gradually disappeared over the next $36-72 \mathrm{hr}$.

The purpose of this paper is to describe a method of quantitating mesangial macromolecular uptake and to describe the effects on this mechanism of increased glomerular permeability to protein as induced by aminonucleoside of puromycin (PA). ${ }^{1}$ We found that mesangial function in normal rats is similar to that of the general reticuloendothelial system, whereas nephrotic animals demonstrate increased mesangial macromolecular uptake.

\section{METHODS}

Preparation of radiolabeled aggregated human gamma globulin and nonaggregated human gamma globulin

Human immune serum globulin ${ }^{2}$ (Cohn fraction II), kindly provided by the American National Red Cross, was labeled with ${ }^{125} \mathrm{I}^{3}$ by the chloramine- ${ }^{4}$ method of McConahey and Dixon (13) with one modification as suggested by these authors, ${ }^{5}$ i.e., $0.15 \mathrm{~m}$ phosphate buffer $\mathrm{pH} 7.0$ was employed instead of $0.05 \mathrm{M}$ phosphate buffer. $1 \mathrm{mCi}$ of ${ }^{125} \mathrm{I}$ was used to label each $25 \mathrm{mg}$ of human IgG; $1.0 \mathrm{~g}$ of unlabeled human IgG was added at the end of the labeling procedure before removal of free ${ }^{125} \mathrm{I}$ on a $30 \mathrm{ml}$ Dowex 1-X8 (100200 mesh) column. ${ }^{\circ}$ The efficiency of labeling was approximately $55 \%$ and the quantity of free ${ }^{125} \mathrm{I}$ in the final product was less than $3 \%$. From this labeled protein heat-aggregated human $\operatorname{IgG}$ was prepared according to the methods of Christian $(14,15)$ and Ishizaka, Salmon, and Fudenberg (12) with certain modifications. To each $100 \mathrm{ml}$ of a $2 \%$ human IgG solution, in $0.15 \mathrm{M}$ saline buffer containing 0.01 M sodium phosphate (phosphate-saline buffer), approximately $0.2 \mathrm{mCi}$ of labeled protein was added. This mixture was then heated to $63^{\circ} \mathrm{C}$ for $30 \mathrm{~min}$ and cooled to room temperature. $40 \mathrm{ml}$ of $2.18 \mathrm{M}$ sodium sulphate was added and the mixture was stirred for $30 \mathrm{~min}$. From this point on all procedures were carried out at $4^{\circ} \mathrm{C}$. The resulting precipitate obtained by centrifugation at $3000 \mathrm{~g}$ for 30 min was resuspended in small quantities of cold phosphatesaline buffer and dialyzed against this buffer for $24 \mathrm{hr}$ with three bath changes. The dialyzed protein solution was centrifuged at $104,000 \mathrm{~g}$ for $90 \mathrm{~min}$ and the pellet was resuspended in cold buffer and centrifuged at $5000 \mathrm{~g}$ to remove insoluble protein aggregates. The concentration of the aggregated human $\mathrm{IgG}^{-125} \mathrm{I}\left(\mathrm{AHIgG}^{-125} \mathrm{I}\right.$ ) was determined by the biuret reaction and adjusted to contain $25 \mathrm{mg}$ of protein per milliliter and merthiolate was added to a final concentration of $1: 10,000$. The efficiency of the aggregation process was approximately $25 \%$. The free ${ }^{125} \mathrm{I}$ of the final $\mathrm{AHIgG}^{125} \mathrm{I}$ preparation was less than $1 \%$ and the

${ }^{1}$ Abbreviations used in this paper: AHIgG- ${ }^{125} \mathrm{I}$, radiolabeled aggregated human IgG; GBM, glomerular basement membrane; $\mathrm{NAHIgG}^{-125} \mathrm{I}$, radiolabeled nonaggregated human IgG; PA, aminonucleoside of puromycin; PAS, periodic acid-Shiff; RES, reticuloendothelial system; TCA, trichloroacetic acid.

${ }^{2}$ E. R. Squibb \& Sons, New Brunswick, N. J.

${ }^{3}$ New England Nuclear Corp., Boston, Mass.

- Eastman Organic Chemicals, Rochester, N. Y.

${ }^{5}$ Personal communication.

- Bio-Rad Laboratories, Richmond, Calif. specific activity of the material was about $0.1 \mu \mathrm{Ci}$ per milligram protein. The AHIgG- ${ }^{125} \mathrm{I}$ was stored at $4^{\circ} \mathrm{C}$ and used within 1 wk of preparation. Bacterial cultures of this material were consistently negative.

Nonaggregated human IgG- ${ }^{125} \mathrm{I}$ (NAHIgG- ${ }^{125} \mathrm{I}$ ) of similar specific activity to the $A H I g G-{ }^{125} \mathrm{I}$ was also adjusted to 25 $\mathrm{mg}$ of protein per milliliter.

\section{Experimental design}

Kinetic studies of mesangial function in normal and nephrotic rats. Nine groups of 10 rats each (male, SpragueDawley, $100 \mathrm{~g}$ ) were given daily subcutaneous injections of $1.5 \mathrm{mg}$ of $\mathrm{PA}^{7}$ in $1.0 \mathrm{ml}$ of $0.9 \mathrm{M} \mathrm{NaCl}$ for 10 days and for each of these groups an additional 10 rats served as controls. After the last injection, all aminonucleoside animals had marked proteinuria and were clinically nephrotic. $24 \mathrm{hr}$ after the last PA dose, the nephrotic animals and their concurrent controls were each given AHIgG- ${ }^{125} \mathrm{I}$ in a dose of $0.25 \mathrm{mg}$ per gram body weight by tail vein injection. Phenergan was administered intraperitoneally to the animals $5 \mathrm{~min}$ before the AHIgG- ${ }^{125} \mathrm{I}$ injection in a dose of $0.005 \mathrm{mg}$ per gram body weight, since this was shown to decrease the incidence of death after aggregate administration. Nephrotic and control animals were sacrificed in groups of 10 at $1,2,4,16,36$, and $72 \mathrm{hr}$ and $1 \mathrm{wk}$ $(168 \mathrm{hr})$ after aggregate administration. Two groups of 10 nephrotic and 10 control animals each were studied $8 \mathrm{hr}$ after AHIgG- ${ }^{125}$ I injection. All the animals survived the aggregate injection except for four aminonucleoside animals in the $36 \mathrm{hr}$ group.

The relationship of mesangial function to proteinuria in rats with aminomucleoside nephrosis. Three groups of 10 rats each were given daily subcutaneous injections of 1.5 $\mathrm{mg}$ of PA. The first group received PA for 4 days, the second for 6 days, and the third for 10 days. 30 animals in three groups of 10 rats each served as concurrent controls. Urine was collected from PA and control animals by placing them in metabolic cages without food but with free access to water for $24 \mathrm{hr}$. The cages were rinsed with water and values for $24 \mathrm{hr}$ urinary excretion of protein from this total collection were determined by the biuret reaction on trichloroacetic acid (TCA)-precipitable protein (16). The animals were then given AHIgG- ${ }^{125} \mathrm{I}$ in a dose of $0.25 \mathrm{mg}$ per gram body weight intravenously and sacrificed $8 \mathrm{hr}$ later by cervical dislocation.

Nonaggregated protein injection in normal and nephrotic rats. 20 animals were given $\mathrm{PA}$ for 10 days and were then injected intravenously with $\mathrm{NAHIgG-}{ }^{125} \mathrm{I}$ in a dose of $0.25 \mathrm{mg}$ per gram body weight. 20 normal rats served as controls and received only the NAHIgG- ${ }^{-125} \mathrm{I}$ injections. All animals in this experiment were sacrificed at $8 \mathrm{hr}$ after NAHIgG- ${ }^{125} \mathrm{I}$ administration.

\section{Immunofluorescent studies}

Immediately after sacrifice the kidneys were removed and a cortical slice was placed in formalin for paraffin embedding and subsequent staining with hematoxylin and eosin and periodic acid-Shiff (PAS) reaction. Part of the kidney was immediately frozen in isopentane precooled in liquid nitrogen, sectioned at $4 \mu$ in a Lipshaw cryostat, and processed for immunofluorescence with appropriate controls according to methods previously described (6) using fluorescein-isothiocyanate-labeled rabbit antisera against human

${ }^{7}$ Nutritional Biochemicals Corporation, Cleveland, Ohio. 
IgG. The amount of immunofluorescence was arbitrarily graded as negative, trace, $1+, 2+, 3+$, and $4+$; photographs were taken as previously described (6).

\section{Glomerular isolation}

Each glomerular isolate was prepared from a pool of the kidneys of five PA or control animals as previously described (17). A mash of decapsulated kidneys was pushed through a 150 mesh monel screen, ${ }^{8}$ the resulting suspension was poured through a 100 monel screen to exclude large tissue fragments and tubules, and the glomeruli were collected on a 200 mesh screen, washed vigorously with a jet of $0.15 \mathrm{M}$ sodium chloride, and rinsed into a $50 \mathrm{ml}$ centrifuge tube. An aliquot was examined by phase contrast microscopy to ensure that at least $85 \%$ purity of the preparation was obtained. The glomeruli were then washed four times with distilled water, lyophilized, weighted, and counted in a crystal scintillation counter for ${ }^{125} \mathrm{I}$. The data were expressed as micrograms $\mathrm{AHIgG-}{ }^{125} \mathrm{I}$ per milligram dried glomeruli plus or minus standard error. In four homogenized glomerular preparations more than $98 \%$ of the counts were precipitable by TCA.

Preparation of lung, liver, spleen, and blood for counting for ${ }^{125} \mathrm{I}$

Samples of lung, liver, and spleen were obtained from each animal at the time of sacrifice. These tissues were washed twice in isotonic saline, dried in a ventilated oven overnight at $85^{\circ} \mathrm{C}$, weighed, and dissolved in $1.0 \mathrm{~N}$ sodium hydroxide containing $0.2 \mathrm{~N}$ sodium deoxycholate with heating at $95^{\circ} \mathrm{C}$ for $1 \mathrm{hr}$. The dissolved tissue was then cooled to room temperature and counted for ${ }^{125} \mathrm{I}$ and the data expressed as micrograms $\mathrm{AHIgG}^{-{ }^{125} \mathrm{I}}$ per milligram dried tissue.

Blood was obtained by cardiac puncture in ether-anesthetized animals just before sacrifice. 50 - or $100-\mu 1$ whole blood samples were added to $2.0 \mathrm{ml}$ of $0.1 \%$ sodium carbonate to produce hemolysis. After total counts for ${ }^{125} \mathrm{I}$ were obtained, $2.0 \mathrm{cc}$ of $10 \% \mathrm{TCA}$ was added to produce protein precipitation. The samples were centrifuged at $5000 \mathrm{~g}$ and the supernatant separated and counted to determine free ${ }^{125} \mathrm{I}$; protein-bound counts were calculated by subtraction.

\section{RESULTS}

Kinetic studies of mesangial function in normal and nephrotic rats

Immunofluorescent microscopy. All aminonucleoside rats in this experiment received PA for 10 days. Nephrotic and control rats were sacrificed at intervals of from 1 to $168 \mathrm{hr}$ after $A H I g G-{ }^{125} \mathrm{I}$ administration. At $1 \mathrm{hr}$ all animals studied had human IgG widely distributed within the glomerular and peritubular capillaries. The glomerular staining appeared to be localized to the capillary lumen, probably in a subendothelial location (Fig. 1a). At $2 \mathrm{hr}$ little peritubular and glomerular capillary luminal staining was evident and IgG was present along the endothelium and within the mesangium. By $4 \mathrm{hr}$ human IgG was found almost entirely within the

${ }^{8}$ Michigan-Dynamics, Inc., Detroit, Mich. glomeruli and in a mesangial distribution with staining in the center of the glomerular lobules in an arborizing pattern which radiated toward the glomerular hilum in the region of the afferent and efferent arteriole. Rarely, arteriolar staining was seen (Fig. $1 b$ ); no fluorescence was seen in peritubular capillaries, tubular lumina, Bowman's space, in the area of the capillary loop, or within or along the glomerular basement membrane (GBM). Thus from 4 to $168 \mathrm{hr}$ the results in Table I may be considered as a comparison, between PA and control kidneys, of the intensity of mesangial deposits of IgG. These results reveal increased mesangial localization of human IgG at each of the time periods from 4 to $168 \mathrm{hr}$ (Fig. $1 c$ and $d$ ). As the intensity of mesangial fluorescence diminished with time the axial and central portion of the mesangium lost the staining more rapidly, leaving only the peripheral areas positive for IgG (Fig. $1 e$ and $f$ ).

Glomerular isolations. Glomerular levels of AHIgG${ }^{125}$ I were similar in control and nephrotic animals sacrificed $1 \mathrm{hr}$ after aggregate administration (Fig. 2). Thereafter levels in nephrotic glomeruli were consistently higher than control values. The $\mathrm{AHIgG}{ }^{-125} \mathrm{I}$ content of nephrotic glomeruli rose steadily during the early hours after injection to peak at $8 \mathrm{hr}$ at a mean (four preparations) of $5.04 \pm 0.57 \mu \mathrm{g} \mathrm{AHIgG-}{ }^{125} \mathrm{I}$ per $\mathrm{mg}$ glomeruli; control values generally fell over this time period to a mean (four preparations) of $0.535 \pm 0.025 \mu \mathrm{g} \mathrm{AHIgG}{ }^{-25} \mathrm{I}$ per mg glomeruli.

After $8 \mathrm{hr}$ there were no differences between the falloff slope derived from the data of the PA glomerular isolates $(-1.232 \pm 0.137)$ and that of control preparations $(-0.856 \pm 0.206)(0.1<P<0.2)$.

Lung, liver, spleen, and blood. During the first $8 \mathrm{hr}$ after the administration of $\mathrm{AHIgG}-{ }^{125} \mathrm{I}$, at a time when there were striking differences in glomerular uptake between control and PA animals, there were no significant differences in lung, liver, or spleen uptake (Fig. 2). At subsequent time periods slight differences $(P<0.01)$ were seen only at $168 \mathrm{hr}$ in lung (control values higher than $\mathrm{PA}$ ) and at $36 \mathrm{hr}$ in liver (PA values higher than control).

Blood levels of aggregates decreased rapidly from the values at $1 \mathrm{hr}$ so that by $8 \mathrm{hr}$ only $4.9 \%$ of the 1 -hr level was still circulating in PA animals and $5.2 \%$ in control. Significant differences did not occur at the 1-, 2-, 4-, or 8 -hr time periods (Fig. 3). However at 16, 36, 72, and $168 \mathrm{hr}$ blood levels in PA animals were consistently and significantly lower than those in control rats $(P<0.001)$.

Comparison of falloff rates from lung, liver, spleen, and blood. Simple linear regression analyses of falloff slopes derived from data for lung, liver, spleen, and blood from the 8 - to 168 -hr time periods showed no 

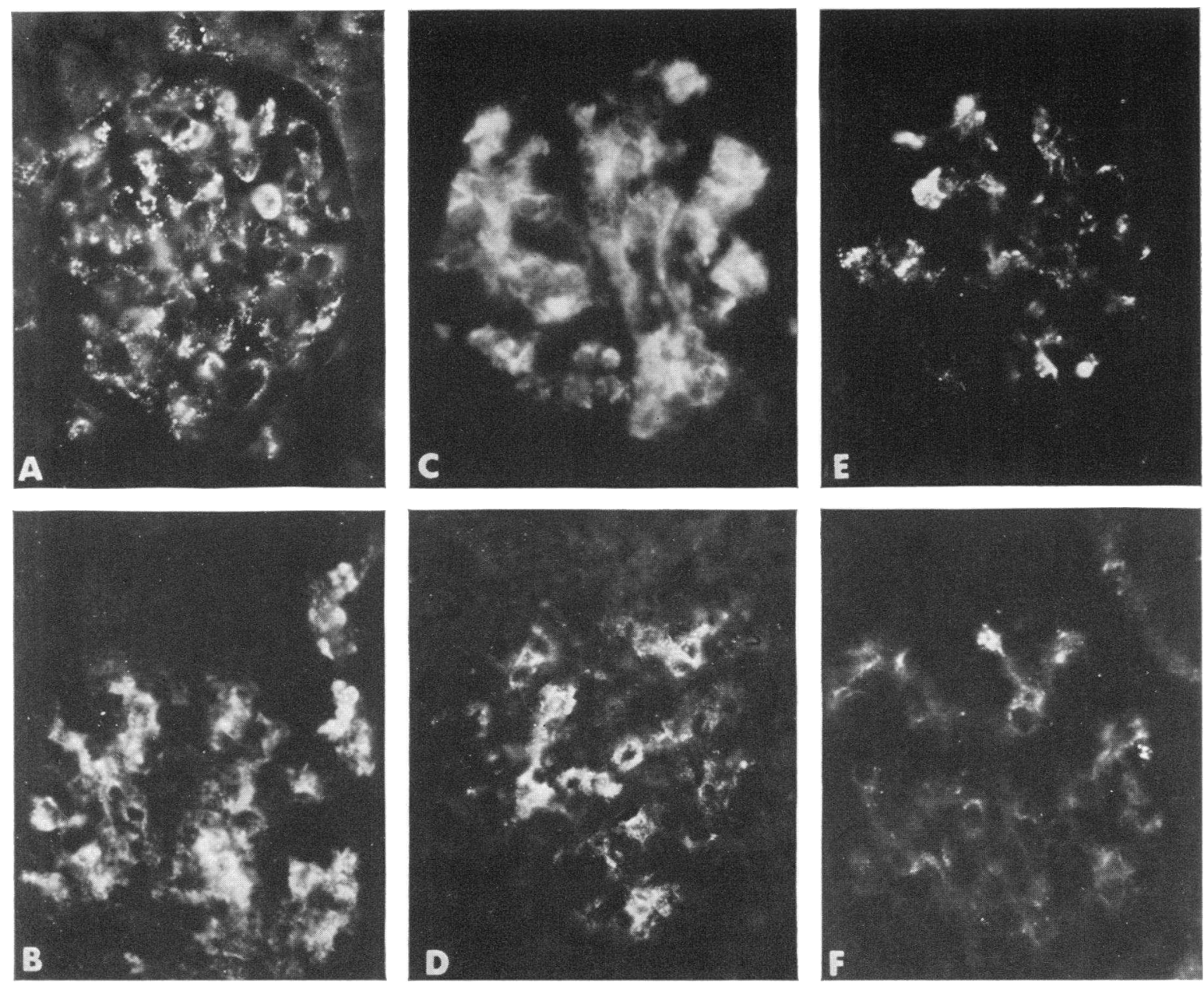

FIGURE 1 Immunofluorescent photomicrographs of glomeruli from: (a) a control rat $1 \mathrm{hr}$ after AHIgG- ${ }^{125}$ I administration showing localization of human IgG along the capillary endothelium and in peritubular capillaries; (b) a nephrotic rat $4 \mathrm{hr}$ after AHIgG- ${ }^{125} \mathrm{I}$ administration showing localization of human IgG in the glomerular mesangium and afferent arteriole; (c) a nephrotic rat $8 \mathrm{hr}$ after $\mathrm{AHIgG-}{ }^{125} \mathrm{I}$ administration showing intense staining for human IgG only in the glomerular mesangium; $(d)$ a control rat $8 \mathrm{hr}$ after AHIgG- ${ }^{125} \mathrm{I}$ administration showing considerably less glomerular mesangial localization of human IgG as compared with Fig. $1 c ;(e)$ a nephrotic rat $36 \mathrm{hr}$ after $\mathrm{AHIgG}-{ }^{125} \mathrm{I}$ administration showing a reduction of the human IgG localized in the glomerular mesangium as compared with Fig. $1 b$ and Fig. $1 c ;(f)$ a control rat $36 \mathrm{hr}$ after $\mathrm{AHIgG-}{ }^{125} \mathrm{I}$ administration showing less glomerular mesangial localization of human IgG as compared with the $36 \mathrm{hr}$ nephrotic glomerulus (Fig. ic) and the $8 \mathrm{hr}$ control glomerulus (Fig. 1d). The tubular staining seen above the glomerulus represents autofluorescence.

significant differences between tissues of PA and control groups.

Relationship of mesangial function to proteinuria in rats with aminonucleoside nephrosis

Urinary protein excretion. Values for $24 \mathrm{hr}$ urinary excretion of protein in animals treated with PA for 4 days did not differ significantly from controls (Table II). 6-day PA rats had minimal proteinuria but differed significantly from controls $(P<0.001)$. After 10 days of PA administration all rats were clinically nephrotic and the mean urinary protein excretion was more than 60 times that of controls (Table II).

Immunofluorescent microscopy. $8 \mathrm{hr}$ after $\mathrm{AHIgG}-{ }^{-25} \mathrm{I}$ administration the pattern of human IgG localization in the kidneys of PA and control animals was qualitatively similar and was present only in the glomerular mesangium. 
TABLE I

Intensity of Glomerular Staining for Human IgG at Various Time Intervals after Aggregated Human $I g G(A H I g G-125 I)$ Administration

\begin{tabular}{|c|c|c|c|c|c|c|}
\hline \multirow{2}{*}{\multicolumn{2}{|c|}{$\begin{array}{c}\text { Hours after } \\
\text { AHIgG-125 I admin- } \\
\text { istration }\end{array}$}} & \multicolumn{5}{|c|}{ Intensity of glomerular staining for human IgG } \\
\hline & & \multirow[t]{3}{*}{ Trace } & \multirow[t]{3}{*}{$1+$} & \multirow[t]{2}{*}{$2+$} & \multirow{2}{*}{$\frac{3+}{5}$} & \multirow[t]{3}{*}{$4+$} \\
\hline 1 & $\mathrm{PA}^{*}$ & & & & & \\
\hline & Control & & & 2 & 3 & \\
\hline \multirow[t]{2}{*}{2} & PA & & & 2 & 3 & \\
\hline & Control & & 2 & 3 & & \\
\hline \multirow[t]{2}{*}{4} & $\mathrm{PA}$ & & & & & 5 \\
\hline & Control & & & 1 & 4 & \\
\hline \multirow[t]{2}{*}{8} & PA & & & & 3 & 2 \\
\hline & Control & & & 5 & & \\
\hline \multirow[t]{2}{*}{16} & PA & & & 1 & 4 & \\
\hline & Control & & 5 & & & \\
\hline \multirow[t]{2}{*}{36} & PA & & 2 & 3 & & \\
\hline & Control & 2 & 3 & & & \\
\hline \multirow[t]{2}{*}{72} & PA & & 3 & 2 & & \\
\hline & Control & 3 & 2 & & & \\
\hline \multirow[t]{2}{*}{168} & $\mathrm{PA}$ & 1 & 4 & & & \\
\hline & Control & 3 & 2 & & & \\
\hline
\end{tabular}

* Five animals were studied from each of the PA and control groups. The numbers represent the number of animals per group with a given intensity of fluorescence on a scale of trace to $4+$. PA animals received aminonucleoside for 10 days.

The intensity of mesangial staining for IgG was similar within the three control groups (Table II). Of the 30 control kidneys studied 25 had intensity ratings of
$1+$ or $2+$, five were $3+$, and none were $4+$. No clear distinction could be made between the kidneys of 4-day, 6-day, and 10-day aminonucleoside animals. However, in these specimens the intensity of mesangial staining was clearly greater than controls. 27 kidneys were rated at $3+$ or $4+$, only three were $2+$, and none were $1+$.

Glomerular levels of $A H I g G{ }_{-}^{125} I$. Values for AHIgG${ }^{125} \mathrm{I}$ in glomeruli isolated from 4-, 6-, and 10-day aminonucleoside rats were considerably higher than those obtained from control animals (Table II). However, one of the control values from the 4 day experiment $(3.19 \mu \mathrm{g}$ AHIgG- ${ }^{125} \mathrm{I}$ per $\mathrm{mg}$ glomeruli) was much higher than that obtained in more than 20 control glomerular isolations. For this reason the 4-day PA studies were repeated and values from experimental animals of 4.23 and $5.88 \mu \mathrm{g} \mathrm{AHIgG-}{ }^{125}$ per $\mathrm{mg}$ glomeruli were clearly higher than concurrent controls which were 1.62 and 1.74 .

There was excellent correlation between the intensity of mesangial fluorescence and glomerular levels of AHIgG- ${ }^{125} \mathrm{I}$ obtained by counting glomerular isolates (Table II).

AHIgG- ${ }_{-}^{125} I$ in lung, liver, spleen, and blood. There were no significant differences in the levels of $\mathrm{AHIgG-}{ }^{125} \mathrm{I}$ in liver, spleen, or blood on comparing 4-day aminonucleoside animals with controls (Table III). The level in the lungs of control animals in the 4 day PA experiment were higher than control $(0.001<P<0.005)$.

In the 6 day PA experiment lung, spleen, and blood studies showed no differences; however the AHIgG ${ }^{-25} \mathrm{I}$ level in the liver of nephrotic animals was higher than controls $(0.001<P<0.005)$ (Table III).

Studies of lung, liver, spleen, and blood levels in 10-

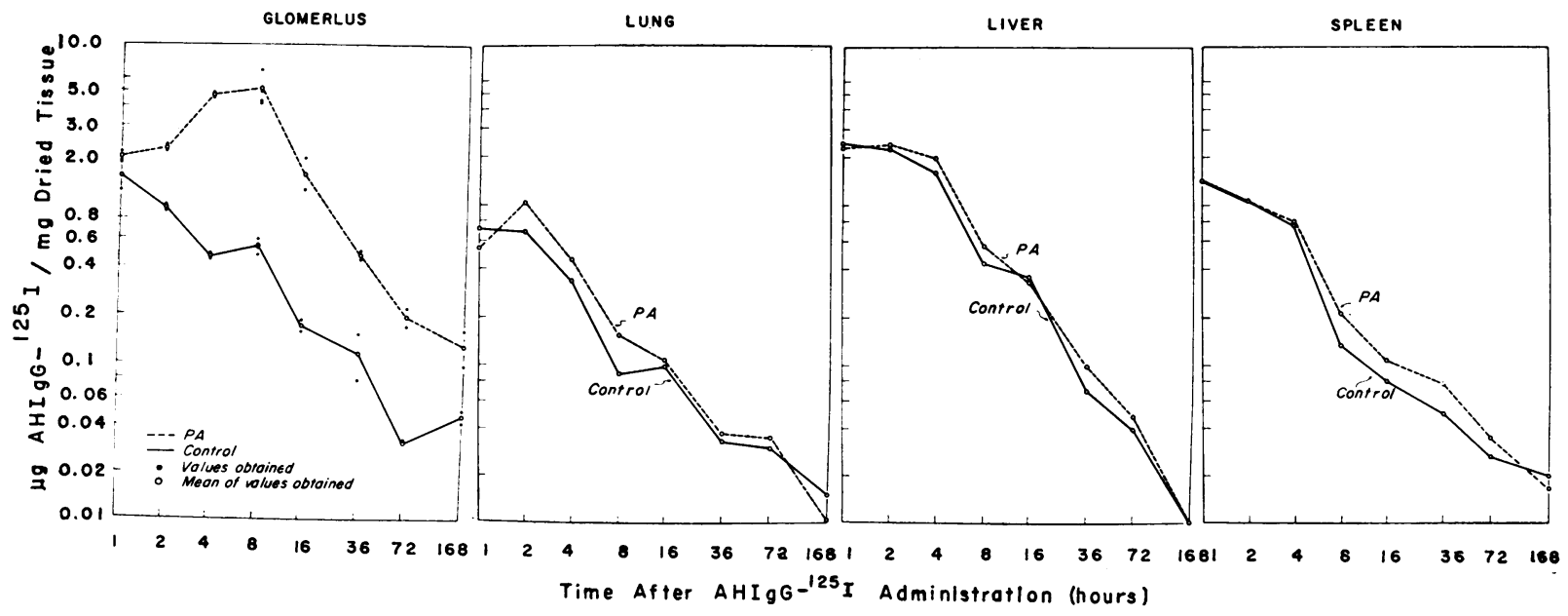

FIGURE 2 AHIgG- ${ }^{125} \mathrm{I}$ in preparations of isolated glomeruli and in the lungs, livers, and spleens in normal and nephrotic rats at varying time intervals after aggregate administration. 


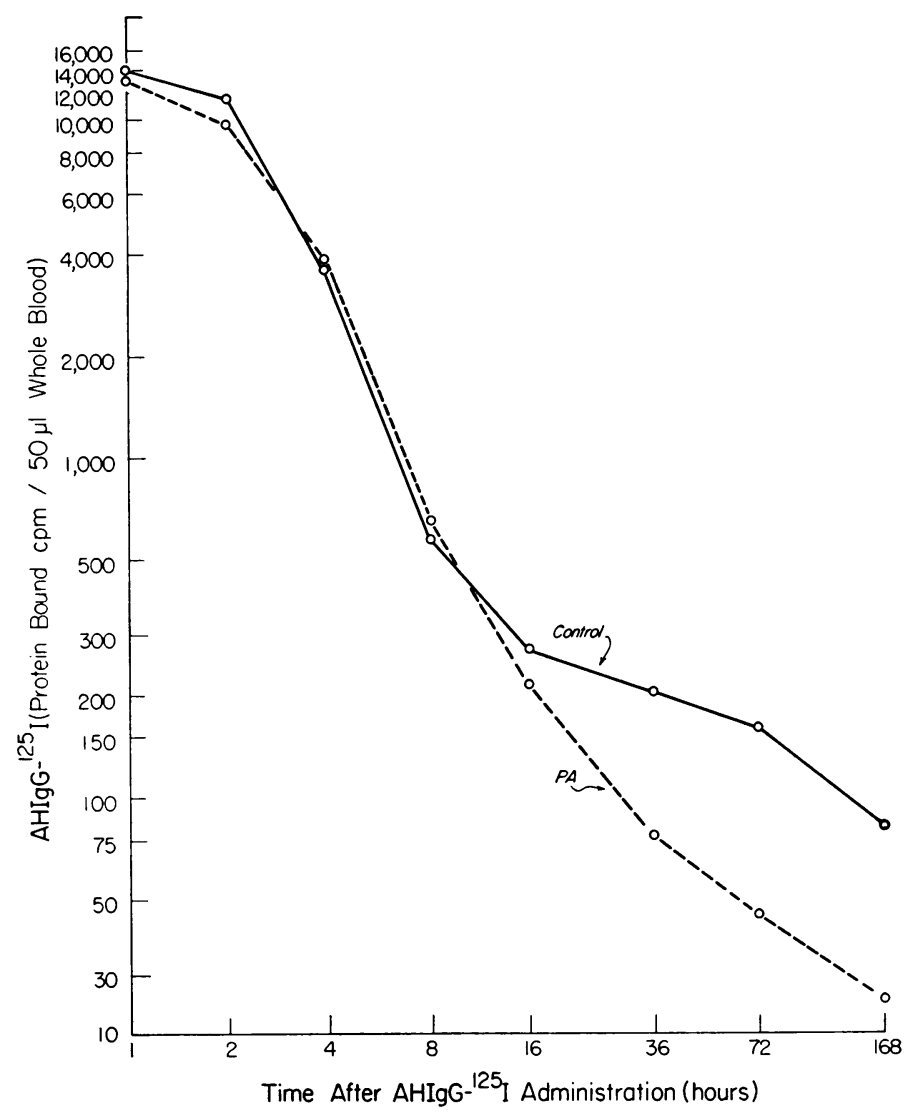

FIGURE 3 AHIgGI- ${ }^{125} \mathrm{I}$ in the blood of normal and nephrotic rats at varying time intervals after aggregate administration.

day nephrotic animals and controls were presented above (Fig. 2).

Nonaggregated protein injection in normal and nephrotic rats

In this experiment, 20 10-day aminonucleoside animals and 20 controls received NAHIgG- ${ }^{125} \mathrm{I}$ and were sacrificed $8 \mathrm{hr}$ later. Immunofluorescent microscopy revealed little renal localization. Slight fluorescence was seen in the peritubular capillaries of most animals and minimal staining was seen in glomerular capillary lumina. Mesangial localization in trace quantities was observed in some animals. There was no difference in the immunofluorescent findings of nephrotic as compared to control kidneys.

Glomerular levels of NAHIgG- ${ }^{125} \mathrm{I}$ were similar in both groups with mean nephrotic and control values of 1.00 and $0.93 \mu \mathrm{g} \mathrm{NAHIgG-}{ }^{125} \mathrm{I}$ per $\mathrm{mg}$ glomeruli respectively (Table IV). No differences were found in liver, spleen, or blood values but there was a silghtly higher concentration of NAHIgG- ${ }^{125} \mathrm{I}$ in the lungs of nephrotic rats $(P<0.01)$.

\section{DISCUSSION}

The mesangial or "third cell" system of the glomerulus has been well defined anatomically as occupying a strategic intercapillary position in the glomerular stalk with cytoplasmic processes extending for some distance and in several directions between the endothelial cell and the GBM (2). Individual mesangial cells are separated from one another by amorphous fibrillar PAS-positive material of unknown composition, the mesangial matrix. Despite the important involvement of this cell system in several pathological states little is known of its functional significance. Substances entering the glomerulus via the afferent arteriole may be filtered, excluded and passed into the efferent arteriole, or may be "trapped" in the glomerulus in or along the GBM, or may pass into the mesangium. The study of the mesangial mechanisms involved in the glomerular handling of macromolecular substances has previously been approached by anatomical techniques $(2,8,9,10,11)$. In this report an attempt was made to apply quantitative methodology to the examination of the kinetics of mesangial uptake (afferent 
TABLE II

Relationship of Mesangial Uptake of Aggregated Human IgG (AHI-125I) to Proteinuria in Rats after Aminonucleoside of Puromycin (PA) Administration

\begin{tabular}{|c|c|c|c|c|c|c|c|c|}
\hline & & \multirow{2}{*}{$\begin{array}{l}\text { Urinary } \\
\text { protein } \\
\text { excretion }\end{array}$} & \multicolumn{4}{|c|}{$\begin{array}{c}\text { Intensity of mesangial } \\
\text { staining for human IgG } \\
\text { by immunofluorescent } \\
\text { microscopył }\end{array}$} & \\
\hline & & & $1+$ & $2+$ & $3 \div$ & $4+$ & \multicolumn{2}{|c|}{$\begin{array}{l}\text { Glomerular } \\
\text { AHIgG-125I }\end{array}$} \\
\hline & & $m g / 2+h r^{*}$ & & & & & $\begin{array}{r}\mu g / \\
\text { glom }\end{array}$ & $\begin{array}{l}m g \\
\text { ruli§ }\end{array}$ \\
\hline \multirow[t]{2}{*}{$\begin{array}{l}\text { Day } 4 \\
\text { of PA } \\
\text { admin. }\end{array}$} & $\begin{array}{c}\text { PA } \\
N=10\end{array}$ & $\begin{array}{c}3.3 \\
(1.9-6.1) \\
N=10\end{array}$ & () & 1 & 6 & 3 & $\begin{array}{l}3.33 \\
4.36\end{array}$ & $\begin{array}{l}4.23 \\
5.88\end{array}$ \\
\hline & $\begin{array}{l}\text { Control } \\
N=10\end{array}$ & $\begin{array}{c}2.1 \\
(1.6-3.0) \\
N=7\end{array}$ & 2 & 6 & 2 & 0 & $\begin{array}{l}3.19 \\
1.49\end{array}$ & $\begin{array}{l}1.62 \\
1.74\end{array}$ \\
\hline \multirow[t]{2}{*}{$\begin{array}{l}\text { Day } 6 \\
\text { of PA } \\
\text { admin. }\end{array}$} & $\begin{array}{c}P A \\
N=10\end{array}$ & $\begin{array}{c}16.0 \\
(3.8-75) \\
N=10\end{array}$ & 0 & 1 & 4 & 5 & $\begin{array}{l}9.2 \\
5.9\end{array}$ & \\
\hline & $\begin{array}{l}\text { Control } \\
N=10\end{array}$ & $\begin{array}{c}2.4 \\
(1.2-7.1) \\
N=7\end{array}$ & 4 & 5 & 1 & 0 & $\begin{array}{l}1.1 \\
2.0\end{array}$ & \\
\hline \multirow[t]{2}{*}{$\begin{array}{l}\text { Day } 10 \\
\text { of PA } \\
\text { admin. }\end{array}$} & $\begin{array}{c}\mathrm{PA} \\
\mathrm{N}=10\end{array}$ & $\begin{array}{c}109 \\
(22.7-204) \\
N=10\end{array}$ & 0 & 1 & 4 & 5 & $\begin{array}{l}4.5 \\
5.9\end{array}$ & \\
\hline & $\begin{array}{l}\text { Control } \\
N=10\end{array}$ & $\begin{array}{c}1.7 \\
(0.2-4.9) \\
N=8\end{array}$ & 4 & 4 & 2 & 0 & $\begin{array}{l}1.0 \\
1.3\end{array}$ & \\
\hline
\end{tabular}

* Protein excretion expressed as mean and range. $N=$ number of animals tested.

¥ The PA and control groups contain 10 rats each. The numbers represent the number of animals per group with a given intensity of fluorescence on a scale of $1+$ to $4+$.

$\$$ Each value represents the concentration of $\mathrm{AHIgG-125} I$ in one glomerular isolation from a pool of kidneys of five animals. All animals were sacrificed $8 \mathrm{hr}$ after AHIg-125I administration.

$\|$ Values derived from repeat of the 4 day PA experiment. limb) and loss (efferent limb) of a macromolecular material in the normal and injured glomerulus.

The glomerular levels of intravenously administered radiolabeled immunoglobulin aggregates (AHIgGI- ${ }^{125} \mathrm{I}$ ) were measured in isolated glomeruli from normal and nephrotic rats and results of these studies were correlated with qualitative immunofluorescent observations. Using the latter technique, the findings, in mice, of Michael et al. (11), which demonstrated the importance of the mesangium in the glomerular handling of protein macromolecules, were confirmed. In the early time periods after aggregate administration considerable quantities of IgG were seen in the region of the peripheral capillary loop. The immunofluorescent technique does not allow precise localization of this material which may have been in the capillary lumen, the GMB, or the subendothelial space. Previous electron microscopic studies, however, support the latter possibility (18). $4 \mathrm{hr}$ after infusion, the IgG was localized entirely within the glomerulus and was confined almost totally to the mesangial area. In normal rats peak glomerular concentrations of AHIgG ${ }^{-25} \mathrm{I}$ are comparable to those of lung, liver, and spleen and the falloff rates from these tissues are similar. These data suggest that, at least with large quantities of circulating macromolecules, the mesangial cell system is an analogue of the general reticuloendothelial system (RES). Benacerraf, McCluskey, and Patras (9) demonstrated glomerular localization of colloidal carbon only after prior "overloading" of the RES with repeated large doses of this substance. We have not studied the relationship of the RES to mesangial function with smaller doses of AHIgG- ${ }^{125} \mathrm{I}$.

The mechanism of macromolecular uptake and transport by the mesangium in normal animals is unclear.

TABLE III

Aggregated Human IgG (AHIgG-125I) in Lung, Liver, Spleen, and Blood in Aminonucleoside (PA) and Normal Rats

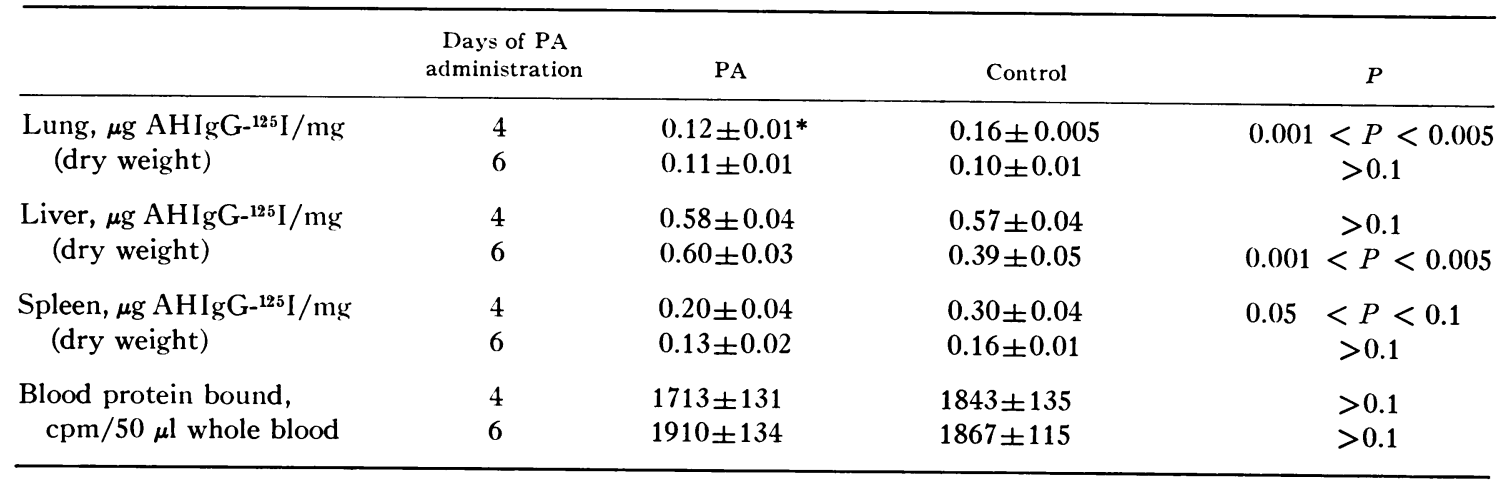

All animals were sacrificed at $8 \mathrm{hr}$ after $\mathrm{AHIgG-}{ }^{-125} \mathrm{I}$ administration.

* $\mathrm{N}=10$ for all lung, liver, spleen, and blood studies. Number presented is mean of 10 values plus or minus standard error. 
Farquhar, Wissig, and Palade found ferritin in the mesangial matrix and in vacuoles within the cytoplasm of mesangial cells within $15 \mathrm{~min}$ after injection into the circulation of normal rats (18). Vernier and BirchAnderson (19) demonstrated the rapid transport of ferritin and colloidal carbon into the mesangial cells of the human fetus minutes after intravascular administration. Similar results have been obtained with other substances including thorotrast, human globin, and colloidal iron. Michael et al. (11) observed by electron microscopy that, in mice, ferritin-labeled protein aggregates appeared within channels between glomerular mesangial cells as opposed to direct cellular phagocytosis. The precise relationships of particle type, size, and charge to the mesangial transport and phagocytic mechanisms remain to be determined.

The mechanism of loss of aggregates from the mesangium with time is unknown but may be due to local digestion and/or transport out of glomerulus. The recent demonstration by Barajas (20) that the mesangium extends into and fills the space between the afferent and efferent arterioles at the glomerular hilum and has extensive contact with the distal tubule and macula densa provides an anatomical pathway out of the glomerulus which could be related to the renal lymphatic system.

Rats made nephrotic by 10 days of PA administration have a marked increase in the mesangial localization of $\operatorname{IgG}$ by immunofluorescent microscopy and by direct counting of $\mathrm{AHIgG}{ }^{125} \mathrm{I}$ in preparations of isolated glomeruli. This confirms the electron microscopic observations of Farquhar and Palade (21) demonstrating greater mesangial deposition of intravenously administered ferritin in rats made nephrotic with PA. Peak glomerular uptake in nephrotic rats occurred at $8 \mathrm{hr}$ after aggregate administration, whereas glomerular levels in control rats fell over this time period so that at $8 \mathrm{hr} \mathrm{AHIgG-}{ }^{125} \mathrm{I}$ in nephrotic glomeruli was 9.4 times that found in control preparations. Levels in nephrotic glomeruli were increasing while blood levels of AHIgG${ }^{125}$ I were rapidly falling suggesting that, in aminonucleoside rats, mesangial uptake can occur with relatively small quantities of circulating aggregates. Our simultaneous studies of $\mathrm{AHIgG}-{ }^{125} \mathrm{I}$ in lung, liver, spleen, and blood in nephrotic and control animals showed no depression of RES function in nephrotic animals. Indeed blood levels of $\mathrm{AHIgG}{ }^{125} \mathrm{I}$ after the $8 \mathrm{hr}$ time period were consistently lower in nephrotic animals. This could reflect urinary loss of protein fragments, increased protein catabolism, increased glomerular uptake, or slight RES stimulation, which could not be detected by our techniques. After $8 \mathrm{hr}$, the falloff of AHIgG ${ }^{125} \mathrm{I}$ from nephrotic glomeruli with time was parallel to that of controls indicating that there was greater mesangial uptake of aggregates rather than diminished rate of loss.
TABLE IV

Nonaggregated Human IgG (NAHIgG-125I) in Glomeruli, Lung, Liver, Spleen, and Blood in Aminonucleoside $(P A)$ and Normal Rats

\begin{tabular}{|c|c|c|c|}
\hline & PA & Control & $P$ \\
\hline $\begin{array}{l}\text { Glomeruli, } \\
\mu \text { g NAHIgG-125I/mg } \\
\text { (dry weight) }\end{array}$ & $\begin{array}{l}1.22 * \\
0.94 \\
0.84\end{array}$ & $\begin{array}{l}1.00 \\
0.99 \\
0.80\end{array}$ & Not done \\
\hline $\begin{array}{l}\text { Lung, } \\
\mu \mathrm{g} \text { NAHIgG-125I/mg } \\
\text { (dry weight) }\end{array}$ & $3.79 \pm 0.11 \ddagger$ & $3.05 \pm 0.22$ & $<0.01$ \\
\hline $\begin{array}{l}\text { Liver, } \\
\qquad \begin{array}{l}\mu \mathrm{g} \text { NAHIgG-125 I/mg } \\
\text { (dry weight) }\end{array}\end{array}$ & $1.39 \pm 0.07$ & $1.75 \pm 0.22$ & $0.05<P<0.1$ \\
\hline $\begin{array}{l}\text { Spleen, } \\
\mu \mathrm{g} \text { NAHIgG-125 } \mathrm{I} / \mathrm{mg} \\
\text { (dry weight) }\end{array}$ & $1.64 \pm 0.06$ & $1.52 \pm 0.11$ & $>0.1$ \\
\hline $\begin{array}{l}\text { Blood protein bound, } \\
\text { cpm/50 } \mu \text { l whole } \\
\text { blood }\end{array}$ & $4135 \pm 186$ & $41.36 \pm 190$ & $>0.1$ \\
\hline
\end{tabular}

PA animals received aminonucleoside for 10 days and all animals were sacrificed $8 \mathrm{hr}$ after NAHIgG-125I administration.

* Each value represents one glomerular isolation from a pool of kidneys of 5 or 10 animals.

$\ddagger N=10$ for all lung, liver, spleen, and blood studies. Number presented is mean of 10 values plus or minus stanciard error.

One possible explanation of the greater uptake in aminonucleoside animals is glomerular endothelial cell damage with increased permeability to macromolecules and consequent exposure of the mesangium to larger quantities of circulating aggregates. However, electron microscopic observations of this cell in PA rats have not revealed pathologic alterations $(22,23)$. Further, with the dose of $\mathrm{AHIgG}{ }^{125} \mathrm{I}$ used in these studies there were no marked differences between nephrotic and control animals in the capillary localization seen in the early time periods after aggregate injection. However, we have found massive capillary type localization in nephrotic animals given larger doses of aggregates $(0.5$ $\mathrm{mg}$ per gram of body weight), while controls showed only mesangial localization (unpublished data). Alternately, the mesangial function may be stimulated directly by PA itself or by increased glomerular capillary permeability to protein. Our studies of the relationship of the quantity of proteinuria to mesangial activity demonstrated increased mesangial uptake after 4 days of PA administration when there was no significant proteinuria. It is possible, however, that increased glomerular permeability to protein was present at this time, but because of tubular reabsorption of protein, this was not reflected in the urine of these animals. There was no difference in the uptake with mild proteinuria (6 days of PA administration) as compared to marked proteinuria (10 days of PA).

Immunofluorescent studies of kidneys after administration of nonaggregated IgG (NAHIgG- $\left.{ }^{125} \mathrm{I}\right)$ demonstrated 
little glomerular localization with most of the IgG present in vascular lumina throughout the tissue. The levels of NAHIgG- ${ }^{125} \mathrm{I}$ in preparations of isolated glomeruli 8 $\mathrm{hr}$ after infusion probably reflect the large quantity of circulating labeled protein present at this time. The absence of significant mesangial deposits of $\mathrm{IgG}$ in either normal or nephrotic animals and the lack of differences between these groups by direct glomerular counts suggest that the phenomena observed with $\mathrm{AHIgG}-{ }^{125} \mathrm{I}$ are specific for macromolecular material.

Germuth, Valdes, Senterfit, and Pollack (24) demonstrated that, in rabbits developing acute serum sickness nephritis, cortisone inhibited the development of glomerulitis and immune complexes localized preferentially in the mesangium as opposed to the subepithelial portion of the capillary loop. These authors theorized that the effect of cortisone was to diminish glomerular basement membrane permeability to circulating immune complexes thus preventing transmigration of these complexes across the filtration barrier for plasma proteins. Our studies clearly demonstrate that increased permeability to protein in aminonucleoside nephrosis is associated with increased mesangial uptake of circulating macromolecules.

It is known that the administration of aminonucleoside results, in most rats, in chronic renal disease with progressive mesangial hyperplasia and lobular sclerosis (25), which is associated with mesangial deposition of host (rat) immunoglobulins and to a lesser extent, complement components $(26,27)$. It is possible that in these animals endogenous circulating immune complexes gain access to the mesangium and eventually produce chronic changes. Focal sclerosis, mesangial proliferative changes, stalk hyalinization, and, eventually, glomerular fibrosis can occur in human glomerulonephritis and nephrotic syndrome. Although there is no direct way of measuring mesangial function in man, the further application of quantitative techniques to the study of mesangial function in animals may provide insights into the relationships between the mesangial cell system and glomerular disease.

\section{ACKNOWLEDGMENTS}

We would like to thank Miss Loretta Schmitz and Miss Mary Surma for their untiring technical assistance, Miss Susan Sisson for her help with the illustrations, Mrs. Janice Aplin for her secretarial assistance, and Dr. Anne Goldman for her aid in performing the statistical analyses.

This work was aided by grants from the National Institutes of Health (AM12375, HE05662, and HE06313) and the American Heart Association. Dr. Mauer's work was supported in part by the National Kidney Foundation.

\section{REFERENCES}

1. Jidaka, K., J. McCoy, and P. Kimmelstiel. 1968. The mesangium: a quantitative analysis. Lab. Invest. 19: 573.
2. Farquhar, M. G., and G. E. Palade. 1962. Functional evidence for the existence of a third cell type in the renal glomerulus. Phagocytosis of filtration residues by a distinctive "third" cell. J. Cell Biol. 13: 55.

3. Urizar, R. E., A. F. Michael, S. Sisson, and R. L. Vernier. 1968. Anaphylactoid purpura. II. Immunofluorescent and electron microscopic studies of the glomerular lesions. Lab. Invest. 19: 437.

4. Michael, A. F., N. G. Westberg, A. J. Fish, and R. L. Vernier. 1971. Studies on chronic membranoproliferative glomerulonephritis with hypocomplementemia. J. Exp. Med. 134 (Suppl.) : 208 s.

5. Kimmelstiel, P. 1968. Diabetic glomerulosclerosis and microangiopathy. Therapeutic Notes. 16: 44.

6. Michael, A. F., K. N. Drummond, R. A. Good, and R. L. Vernier. 1966. Acute poststreptococcal glomerulonephritis: immune deposit disease. J. Clin. Invest. 45: 237.

7. Smith, F. G., Jr., N. Litman, and H. Latta. 1965. Lupus glomerulonephritis: the effect of large doses of corticosteroids on renal function and renal lesions in two children. Amer. J. Dis. Child. 110: 302.

8. Latta, H., and N. B. Maunsbach. 1962. Relations of the centralobular region of the glomerulus to the juxtaglomerular apparatus. J. Ultrastruct. Res. 6: 562.

9. Benacerraf, B., R. T. McCluskey, and D. Patras. 1959. Localization of colloidal substances in vascular endothelium. A mechanism of tissue damage. I. Factors causing the pathologic deposition of colloidal carbon. J. Exp. Pathol. 35: 75 .

10. Menefee, M. G., C. B. Mueller, A. L. Bell, and J. K Meyer. 1964. Transport of globin by the renal glomerulus. J. Exp. Med. 120: 1129.

11. Michael, A. F., A. J. Fish, and R. A. Good. 1967. Glomerular localization and transport of aggregated proteins in mice. Lab. Invest. 17: 14.

12. Ishizaka, T., K. Ishizaka, S. Salmon, and H. Fudenberg. 1967. Biological activities of aggregated gammaglobulin. VIII. Aggregated immunoglobulins of different classes. J. Immunol. 99: 82.

13. McConahey, P. J., and F. J. Dixon. 166. A method of trace iodination of proteins for immunologic studies. Int. Arch. Allergy. 29: 185.

14. Christian, C. L. 1960. Studies of aggregated gammaglobulin. I. Sedimentation, electrophoretic, and anticomplementary properties. J. Immunol. 84: 112.

15. Christian, C. L. 1960. Studies of aggregated gammaglobulin. II. Effect in vivo. J. Immunol. 84: 117.

16. Weichselbaum, T. E. 1946. An accurate and rapid method for the determination of proteins in small amounts of blood or plasma. Amer. J. Clin. Pathol. 16: 40.

17. Blau, E., and A. F. Michael. 1971. Rat glomerular basement composition and metabolism in aminonucleoside nephrosis. J. Lab. Clin. Med. 77: 97.

18. Farquhar, M. G., S. L. Wissig, and G. E. Palade. 1961. Glomerular permeability. I. Ferritin transfer across the normal glomerular capillary wall. J. Exp. Med. 113: 47.

19. Vernier, R. L., and A. Birch-Anderson. 1963. Studies of the human fetal kidney. II. Permeability characteristics of the developing glomerulus. J. Ultrastruct. Res. 8: 66 .

20. Barajas. L. 1970. The ultrastructure of the juxtaglomerular apparatus as disclosed by three dimensional reconstructions from serial sections. J. Ultrastruct. Res. 33: 116. 
21. Farquhar, M. G., and G. E. Palade. 1961. Glomerular permeability. II. Ferritin transfer across the glomerular capillary wall in nephrotic rats. J. Exp. Med. 114: 699.

22. Vernier, R. L., B. W. Papermaster, and R. A. Good. 1959. Aminonucleoside nephrosis. I. Electron microscopic study of the renal lesion in rats. J. Exp. Med. 109: 115.

23. Ericsson, J. L. E., and G. A. Andres. 1961. Electron microscopic studies of the development of the glomerular lesions in aminonucleoside nephrosis. Amer. J. Pathol. 39 : 643.

24. Germuth, F. G., Jr., A. J. Valdes, L. B. Senterfit, and A. D. Pollack. 1968. A unique influence of cortisone on the transit of specific macromolecules across vascular walls in immune complex disease. Johns Hopkins Med. J. $122: 137$.

25. Lannigan, R. 1963. The production of chronic renal disease in rats by a single intravenous injection of aminonucleoside of puromycin and the effect of low dosage continuous hydrocortisone. Brit. J. Exp. Pathol. $44: 326$.

26. Okuda, R., M. H. Kaplan, F. E. Cuppage, and W. Heymann. 1965. Deposition of gamma globulin in kidneys of rats with nephrotic renal disease of various etiologies. J. Lab. Clin. Med. 66: 204.

27. Unanue, E., and F. J. Dixon. 1964. Experimental glomerulonephritis. IV. Participation of complement in nephrotoxic nephritis. J. Exp. Med. 119: 965. 